\title{
Identification and characterization of scirr1, a novel gene up-regulated after spinal cord injury
}

\author{
Tao Liu', Zhenlian $\mathrm{Ma}^{1}$, \\ Haiping Que ${ }^{1}$, Xin $\mathrm{Li}^{1}$, \\ Yanli $\mathrm{Ni}^{1}$, Shuqian Jing ${ }^{1,2}$ \\ and Shaojun $\mathrm{Liu}^{1,3}$ \\ ${ }^{1}$ Department of Neurobiology \\ Institute of Basic Medical Sciences \\ 27 Taiping Road, Beijing 100850, P. R. China \\ ${ }^{2}$ Department of Clinical Immunology \\ Amgen Inc., Thousand Oaks, CA 91320-1799, USA \\ ${ }^{3}$ Corresponding author: Tel, 86-10-66931304; Fax, 86-10-68213039 \\ E-mail, liusj@nic.bmi.ac.cn
}

Accepted 12 March 2007

Abbreviations: aa, amino acid(s); CDS, coding sequence; dpc, days post-coitum; DIG, digoxigenin; EGFP, enhanced green fluorescent protein; EST, expressed sequence tag; FBXL16, F-box and leucine-rich repeat protein 16; GST, glutathione S-transferase; PI, post-injury; SCF, SKP1-CULLIN-F-box complex.; scirr1, spinal cord injury and/or regeneration related gene 1

\begin{abstract}
Spinal cord injury and regeneration involves trans criptional activity of many genes, of which many remain unknown. Using the rat spinal cord fulltransection model, bioinformatics, cloning, expression assays, fusion proteins, and transfection techniques, we identified and characterized one such differentially expressed gene, termed scirr1 (spinal cord injury and/or regeneration related gene 1). Fourteen orthologs were found in 13 species from echinoderm to insect and human by Blast search of NCBI protein reference sequence database. However, no further information is available for these homologues. Using whole-mount in situ hybridization, mouse scirr1 mRNA was expressed temporally and spatially in accordance with the early development sequence of the central nervous system. In adult rat spinal cord, expression of scirr1 mRNA was localized to neurons of gray matter by in situ hybridization. Using immunohistochemistry, SCIRR1 protein was found to be up-regulated and expressed more highly in spinal cord neurons farther from the epicenter of injury. Although the precise function of SCIRR1 is unknown, its unique pattern of expression during
\end{abstract}

CNS early development and up-regulation after spinal cord injury suggest that SCIRR1 should be involved in the succeeding injury and/or repair processes of the injured spinal cord. Also, the typical F-box and leucine-rich repeat (LRR) architecture of rat SCIRR1 indicated that it may play an important substrate recruiting role in the pleiotropic ubiquitin/ proteasome pathway. All these make scirr1 a new interesting start to study the spinal cord injury and regeneration mechanism.

Keywords: embryonic development; gene expression; mice; rats; spinal cord; wounds and injuries

\section{Introduction}

At present, there is no universally accepted treatment for paraplegia caused by injury to the spinal cord, mainly because of the indetermination of many genes believed to be involved in the complex pathophysiology of spinal cord injury and repair (Beattie et al., 2002; Profyris et al., 2004). Genes serving to repair injured spinal cord have been shown to reach their expression peaks 3.5 to 5 days post injury (Hayashi et al., 2000). To identify more genes, especially new ones, underlying the processes after the injury of spinal cord, we made a complete transection model of rat spinal cord and performed an improved subtractive hybridization (Zhao et al., 1999) from cDNA of spinal cord post-transection day 4.5 against that of intact spinal cord as a means of identifying up-regulated genes in the injury and/or regeneration process. A total of forty validated highquality expressed sequence tags (EST) were successfully sequenced. Bioinformatics analysis revealed that eight of these sequences represent novelgenes, which clearly reveals our current deficiency in the understanding of the subsequent processes after spinal cord injury (Ma et al., 2006). It further indicates that we need to continue our investigation into the nature of these functionally uncharacterized new genes, which will enable us to identify potential regulatory genes of spinal cord injury and repair. Our laboratory recently embarked on this laborious task, and we present our findings for one such novel gene, termed scirr1 (spinal cord injury and/or regeneration related gene 1 ).

To infer the potential role of scirr1 in the processes after spinal cord injury, we introduce data deal- 
ing with the molecular cloning and characterization of scirr1, which include scirr1 expression profiles in different developmental stages, and after transection of the adult rat spinal cord. In addition, domain architecture was analyzed to deduce the possible pathway through which SCIRR1 takes its function.

\section{Materials and Methods}

\begin{abstract}
Animals
We studied adult male Wistar rats weighing between 220-250 g, housed in plastic sawdust-covered cages with a normal light/dark cycle and free access to rat chow and water. All protocols were reviewed and approved by Beijing Institute of Basic Medical Sciences using the European Communities Council Directive of 24 November 1986 (86/609/EEC). Experiments were designed to minimize the number of animals required and to minimize animal suffering. Rats were anesthetized with pentobarbital $(60 \mathrm{mg} / \mathrm{kg})$ prior to all procedures.
\end{abstract}

\section{Spinal cord full-transection model}

Adult male Wistar rats, weighing between 220-250 g and at the same age, were anesthetized with sodium pentobarbital $(60 \mathrm{mg} / \mathrm{kg})$. A $\sim 1.8-\mathrm{cm}$ dorsal median incision was made over the thoracic vertebral column. The vertebral arch and the spinous processes of T8-10 were exposed by cutting the caudal part of the nuchal ligament and separating the underlying sacrospinous muscle from its origin of the spinal processes. The medial part of the autochthone musculature was retracted to the side over two segments from the spinal processes and the arches of the vertebra. Exposed by laminectomy, the cord at the T9-10 level was then transected completely with a self-made scalpel $\left(8 \mathrm{~mm}\right.$ blade depth, $\left.15^{\circ}\right)$ in one movement from the right to the left. The autochthone muscles and the sacrospinous muscles of both sides were repositioned and gently opposed by three single sutures using 10-0 nylon thread. With the same suture, the skin was closed. Animals were kept individually and permitted survival for $1,3,4.5$ and 5 days respectively. Sham-operated rats, receiving all operations but with only the transection of spinal cord and dorsal spinal vein, served as controls.

\section{Bioinformatics analysis and cloning of scirr1 coding sequence (CDS)}

The original EST sequence (GenBank Accession no. CV463503) of scirr1 was mapped to chromosome 10q12. The genomic DNA sequence between its flanking genes was chosen for CDS prediction by the GenScan (Burge and Karlin, 1997) and
HMMgene (Krogh, 1997) web servers. The primers were designed using the predicted CDS sequence as template. Total RNA of post-transection day 4.5 rat spinal cord was harvested from a $5-\mathrm{mm}$ segment of spinal cord centered on the point of transection, using the SV Total RNA Isolation System and protocol (Promega, Madison, NJ). First strand cDNA was synthesized with the SuperScript II RNaseH Reverse Transcriptase (Invitrogen, Carlsbad, CA). A PCR reaction was carried out with first strand CDNA and the primers (5'-ATGTCGAGCCCTGGTATC-3' and 5'-CTATTCAATGACGAGGCAG-3') using the following PCR conditions: $60^{\circ} \mathrm{C}$ for $30 \mathrm{~min}, 94^{\circ} \mathrm{C}$ for $2 \mathrm{~min}$, and 40 cycles of $94^{\circ} \mathrm{C}$ for $30 \mathrm{~s}, 65^{\circ} \mathrm{C}$ for $1 \mathrm{~min}$, and $72^{\circ} \mathrm{C}$ for $1 \mathrm{~min}$. The PCR product was subcloned into the pGEM-T vector (Promega, Madison, NJ) and sequenced.

\section{RT-PCR analysis of scirr1 mRNA expression}

RNA was harvested respectively from various fresh rat tissues (skeletal muscle, heart, liver, thymus, spleen, pancreas, kidney, stomach, lung, small intestine, large intestine, testis, cerebra, cerebellum, brain stem and spinal cord) using the SV Total RNA Isolation System and protocol (Promega, Madison, NJ). First strand cDNA synthesis was carried out with the SuperScript II RNaseH Reverse Transcriptase (Invitrogen, Carlsbad, CA) in a volume of $50 \mu \mathrm{l}$ using $2 \mu \mathrm{g}$ of RNA and $125 \mathrm{ng}$ of Oligo (dT) ${ }_{15}$. PCR reaction was then carried out with $2 \mu \mathrm{l}$ of first strand cDNA and the set of scirr1-specific primers (5'GTCGCAAACTTCTCATGGCTAA-3' and 5'-TCGTGCTGGACAGGTGTGTAC-3'). GAPDH was amplified as a control marker with primers (5'-TCCCTCAAGATTGTCAGCAA-3' and 5'-AGATCCACAACGGATACATT-3'). PCR products were separated by $1.2 \%$ agarose gel electrophoresis.

\section{Preparation of scirr1 RNA probe}

Blast search against the rat mRNA database of GenBank revealed that the $147 \mathrm{bp}$ fragment from nucleotides 1,130 to 1,276 is the most specific sequence of the rat scirr1 coding region. This fragment covers the 3' part of the third exon and the 5' part of the fourth exon, which enables probe derived from this fragment to identify scirr1 mRNA specifically. Then this fragment was amplified using primers 5'-CTGGAATTCGTCGCAAACTTCTCATGGCTAA-3' and 5'-TACAAGCTTTCGTGCTGGACAGGTGTGTAC3', and the PCR product was inserted into the pSPT19 vector (Roche, Grenzacherstrasse, Basel, Switzerland) between the EcoRI and HindIII sites. Following verification by DNA sequencing, vectors were linearized by EcoRI and HindIII respectively for sense and antisense digoxigenin-labeled riboprobes 
synthesis by in vitro transcription using the DIG RNA labeling kit (SP6/T7) and protocol (Roche, Grenzacherstrasse, Basel, Switzerland).

\section{In situ hybridization histochemistry}

Adult male Wistar rats, weighing between 220 and $250 \mathrm{~g}$, were anesthetized with sodium pentobarbital $(60 \mathrm{mg} / \mathrm{kg}$ ), perfused through the left atrium with physiological saline weighing twice the rat's weight, and then perfusion-fixed using the same volume of $4 \%$ paraformaldehyde fixative. The spinal cord was taken out, immersion-fixed in $4 \%$ paraformaldehyde at $4^{\circ} \mathrm{C}$ for $4 \mathrm{~h}$, and washed with PBS 4-5 times for 1 h. After immersion at $4^{\circ} \mathrm{C}$ in $30 \%$ sucrose for inhibition of ice crystal formation, the tissues were embedded in optimum cutting temperature (OCT) compound and were frozen in liquid nitrogen. Then 30- $\mu \mathrm{m}$ frozen coronal sections were cut on a CRYOCUT II microtome (American Optical Corp., Buffalo, NY). After washing 3 times with PBS and treatment with $0.1 \mathrm{M}$ glycin in PBS for $5 \mathrm{~min}$, the sections were put in PBS containing $0.3 \%$ TritonX-100 for $30 \mathrm{~min}$. Sections were moved into $1 \mu \mathrm{g} / \mathrm{ml}$ proteinase $\mathrm{K}$ for 5 min and then immersion-fixed with $4 \%$ paraformaldehyde for $10 \mathrm{~min}$. Following 3 washes with PBS, the tissues were acetylated with $0.25 \%$ acetic anhydride for $10 \mathrm{~min}$ and sequentially treated with double strength standard saline citrate $(2 \times \mathrm{SSC}, 1 \times \mathrm{SSC}=$ $0.15 \mathrm{M} \mathrm{NaCl}, 15 \mathrm{mM}$ sodium citrate, $\mathrm{pH} 7.0$ ) for 10 $\mathrm{min}$. Then the sections were incubated in prehybridization solution $(5 \times$ SSC, $50 \%$ formamide, $0.1 \%$ Tween 20, $50 \mu \mathrm{g} / \mathrm{ml}$ heparin, and $100 \mu \mathrm{g} / \mathrm{ml}$ sonicated and denatured salmon sperm DNA) for $4 \mathrm{~h}$ at $42^{\circ} \mathrm{C}$. With the prehybridization solution removed, the sections were incubated with fresh hybridization buffer containing $0.5 \mu \mathrm{g} / \mathrm{ml}$ digoxigenin-labeled RNA probe at $55^{\circ} \mathrm{C}$ in a humid atmosphere for $16 \mathrm{~h}$. Then sections were washed in $2 \times$ SSC at room temperature for $30 \mathrm{~min}$, in $1 \times \mathrm{SSC}$ for $10 \mathrm{~min}$, and in $0.1 \times$ SSC for $10 \mathrm{~min}$. Detection of the probe in the sections was carried out using the DIG nucleic acid detection kit (Roche, Grenzacherstrasse, Basel, Switzerland) basically according to the manufacturer's instructions. Sections incubated with digoxigenin-labeled RNA probe were rinsed 3 times briefly in a washing buffer $(0.1 \mathrm{M}$ Maleic acid, $0.15 \mathrm{M} \mathrm{NaCl}$, $\mathrm{pH} 7.5,0.3 \%(\mathrm{v} / \mathrm{v})$ Tween 20), incubated with a blocking solution $(1 \%(\mathrm{w} / \mathrm{v})$ Roche blocking reagent in washing buffer) for $30 \mathrm{~min}$, incubated with a $5000 \times$ dilution of anti-digoxigenin-AP in blocking solution for $3.5 \mathrm{~h}$, washed with washing buffer two times for $15 \mathrm{~min}$, and finally equilibrated $5 \mathrm{~min}$ in a detection buffer $(0.1 \mathrm{M}$ Tris- $\mathrm{HCl}, 0.1 \mathrm{M} \mathrm{NaCl}, \mathrm{pH}$ 9.5). Then the sections were incubated in darkness with $2 \%(\mathrm{v} / \mathrm{v})$ nitro blue tetrazolium and 5-bro- mo-4-chloro-3-indolyl phosphate (NBT/BCIP) in detection buffer. When the desired spot intensities were achieved, the color development was stopped with sterile double distilled water. Finally, the sections were rinsed with tap water and mounted onto glass slides with $0.3 \%$ glutin. The slides were then dehydrated in alcohol, cleared in xylene, examined with an Olympus BX50 microscope, and photographed using a digital camera (Olympus C7070).

\section{Whole-mount in situ hybridization histochemistry}

To determine the embryonic expression of scirr1 mRNA, whole-mount in situ hybridization was carried out on KM mouse embryos, obtained by timed matings, with noon of the day of the vaginal plug designated as 0.5 days post-coitum (dpc). The pregnant females were killed by cervical dislocation on 9-13 $\mathrm{dpc}$ and the uteri were washed in ice-cold PBS. The embryos were dissected free in $4 \%$ paraformaldehyde/PBS, and fixed in this solution overnight at $4^{\circ} \mathrm{C}$. Embryos were rocked gently at room temperature throughout the procedure on a mechanical rocking platform unless otherwise indicated. The embryos were washed three times with PBS containing $0.1 \%$ (v/v) Tween 20 (PBT), dehydrated into 100\% methanol and stored at $-20^{\circ} \mathrm{C}$. To resume, the embryos were treated with $5: 1$ methanol $/ 30 \%$ hydrogen peroxide for 3 to $5 \mathrm{~h}$. After several washes with methanol, the embryos were rehydrated through a methanol-PBT series and washed three times in PBT. Embryos were treated with $10 \mu \mathrm{g} / \mathrm{ml}$ proteinase $\mathrm{K}$ in PBT for $25 \mathrm{~min}$, followed by washing for $10 \mathrm{~min}$ with PBT. The embryos were refixed in $0.1 \%$ glutaraldehyde and $4 \%$ paraformaldehyde in PBS for 20 min and then washed two times with PBT each for $10 \mathrm{~min}$. The samples were dipped in hybridization buffer $(5 \times$ SSC, $50 \%$ (v/v) formamide, $0.1 \%(\mathrm{v} / \mathrm{v})$ Tween $20,50 \mu \mathrm{g} / \mathrm{ml}$ heparin, $100 \mu \mathrm{g} / \mathrm{ml}$ yeast tRNA and $100 \mu \mathrm{g} / \mathrm{ml}$ denatured salmon sperm DNA) for two hours at $63^{\circ} \mathrm{C}$. Then hybridization was carried out with $0.5 \mu \mathrm{g} / \mathrm{ml}$ digoxigenin-labeled riboprobes in fresh hybridization buffer at $63^{\circ} \mathrm{C}$ for $18 \mathrm{~h}$. After four 15 -min washes with $50 \%(\mathrm{v} / \mathrm{v})$ formamide in $2 \times$ SSC at $63^{\circ} \mathrm{C}$, samples were rinsed with RNase buffer $(0.5$ $\mathrm{M} \mathrm{NaCl}, 10 \mathrm{mM}$ Tris-HCl (pH 7.6), 1 mM EDTA) twice, and then incubated with $20 \mu \mathrm{g} / \mathrm{ml}$ RNase A and $100 \mathrm{U} / \mathrm{ml}$ RNase T1 in RNase buffer at $37^{\circ} \mathrm{C}$ for 20 min. Subsequently, samples were rinsed with $1 \%$ $(\mathrm{v} / \mathrm{v})$ Tween 20 in $2 \times$ SSC 4 times for 15 min each at $63^{\circ} \mathrm{C}$, and then with $1 \%(\mathrm{v} / \mathrm{v})$ Tween 20 in $1 \times$ SSC 4 times for $15 \mathrm{~min}$ each at $63^{\circ} \mathrm{C}$. The embryos were treated with buffer I (100 mM Tris- $\mathrm{HCl}(\mathrm{pH} 7.5), 150$ $\mathrm{mM} \mathrm{NaCl}$ ) for $15 \mathrm{~min}$, washed with $5 \% \mathrm{BSA}$ and $0.1 \%(\mathrm{v} / \mathrm{v})$ Tween 20 in buffer II (137 mM NaCl, 25 $\mathrm{mM}$ Tris- $\mathrm{HCl} \mathrm{pH} \mathrm{7.5,} 3 \mathrm{mM} \mathrm{KCl}$ ) for $4 \mathrm{~h}$, incubated 
with $2,000 \times$ diluted anti-digoxigenin-AP (Roche, Grenzacherstrasse, Basel, Switzerland), 5\% BSA and $0.1 \%(\mathrm{v} / \mathrm{v})$ TritonX-100 in buffer $\mathrm{Il}$ at $4^{\circ} \mathrm{C}$ overnight, washed with $0.1 \%$ TritonX-100 in buffer I four times for $1 \mathrm{~h}$ each, and then equilibrated by four 15-min washes with $2 \mathrm{mM}$ levamisole in buffer III (100 mM Tris-HCl (pH 9.5), $100 \mathrm{mM} \mathrm{NaCl}, 50 \mathrm{mM}$ $\mathrm{MgCl}_{2}$ ). Finally, the embryos were incubated with $2 \%$ (v/v) NBT/BCIP in buffer III for color development. When staining was satisfactory, the embryos were washed twice with sterile double distilled water. After dehydration and background elimination with graded formamide, embryos were cleared in $100 \%$ glycerol. With strong transillumination, embryos were observed and photographed using an Olympus SZX9 dissecting stereo microscope and PM-C35DX camera.

\section{Generation of enhanced green fluorescent protein (EGFP) fusion}

To assess SCIRR1 protein localization, a SCIRR1EGFP fusion protein was constructed. Primers (5'CTCAAGCTTAGCATGTCGAGCCCTGGTATCGA-3' and 5'-GTGGGATCCGGTTCAATGACGAGGCAG-3') containing unique 5' Hindlll and $3^{\prime}$ BamHI restriction sites were designed and used to amplify the complete SCIRR1 coding region except for the stop codon. The amplified fragment was restriction digested and ligated into the pEGFP-N1 vector (Clontech, CA), which is under the control of the CMV promoter and leads to the generation of a fusion protein with SCIRR1 fused to the amino terminus of EGFP. Potential SCIRR1-EGFP plasmids were isolated from transformed cells and screened for the presence of the scirr 1 CDNA insert by PCR. The correct $\left(5^{\prime}-3^{\prime}\right)$ orientation and frame of the scirr1 insertion were then verified by sequencing. Bacterial stock solutions containing the verified SCIRR1EGFP plasmid were used to isolate SCIRR1-EGFP plasmid DNA for the subsequent transfection experiments.

\section{Cell culture and transfection}

Transient transfection studies were performed using PC12 cells maintained in the log growth phase. Cells were plated in standard 6-well tissue culture plates containing glass coverslips at an initial density of 1 $\times 10^{5}$ cells/well and transfected with SCIRR1-EGFP plasmid, facilitated by the addition of the transfection reagent Lipofectamine 2000 (Invitrogen, Carlsbad, $\mathrm{CA}$ ). As a negative control, transfections were carried out in the same manner, using the parental pEGFP-N1 vector. After $48 \mathrm{~h}$, cells were washed, fixed in $4 \%$ paraformaldehyde, mounted, and imaged with epi-fluorescence confocal microscopy
(Bio-Rad Radience 2100) at the National Center of Biomedical Analysis.

\section{Preparation of antiserum against purified SCIRR1}

The whole coding sequence of scirr1 was amplified using a forward primer including the $B a m \mathrm{HI}$ site (underlined), 5'-CGTGGATCCATGTCGAGCCCTGGTATC-3', and a reverse primer including the Xhol site, 5'-CAGCTCGAGCTATTCAATGACGAGGCAG3'. The amplified fragment was digested with $B a m H I$ and $X$ hol and subcloned into pGEX-4T-2 (Amersham Biosciences, Piscataway, NJ), an N-terminal glutathione S-transferase (GST) fusion vector. A transformant of Escherichia coli BL21 (DE3) was cultured to $A_{600}=0.7$ at $37^{\circ} \mathrm{C}$ and maintained in $0.5 \mathrm{mM}$ isopropyl-D-thiogalactopyranoside at $25^{\circ} \mathrm{C}$ for $20 \mathrm{~h}$. The cells were sonicated and centrifuged, and then the supernatant was applied to a GSTrap FF $1 \mathrm{ml}$ column (Amersham Biosciences, Piscataway, NJ). Consequently, the expressed GST fusion protein, which contains a thrombin protease site between the GST and SCIRR1 sequence, was captured on the column. After washing impurities, the fusion protein was incubated on a column with thrombin $(20 \mathrm{U} / \mathrm{ml}$ in $1 \times$ PBS) for $16 \mathrm{~h}$ at $24^{\circ} \mathrm{C}$. Then the target SCIRR1 protein minus the GST moiety was eluted using $1 \times$ PBS and condensed using an Amicon Ultra-4 centrifugal filter unit. Intact GST fusion protein was not detected in the purified SCIRR1 solution by SDS-PAGE. The purified SCIRR1 protein (500 $\mu \mathrm{g})$ was injected hypodermically into a rabbit in Freund's complete adjuvant. After three boosters of the purified SCIRR1 $(125 \mu \mathrm{g})$ in Freund's incomplete adjuvant at 2-week intervals, the anti-SCIRR1 serum was obtained ten days after the last injection. The specificity of antiserum for SCIRR1 was verified by Western blot assay of the purified SCIRR1 and total protein derived from rat spinal cord at 4.5 days post-transection.

\section{Western blot analysis}

Proteins in the samples were separated by SDSPAGE and electrotransferred onto nitrocellulose membrane. Then the membrane was briefly rinsed in a buffer containing $25 \mathrm{mM}$ Tris $\mathrm{HCl}, \mathrm{pH} 7.4,150$ $\mathrm{mM} \mathrm{NaCl}, 3 \mathrm{mM} \mathrm{KCl}$, and $0.02 \%$ (v/v) Tween-20 (TTBS). The membrane was incubated at room temperature for $1 \mathrm{~h}$ in TTBS containing $5 \%(\mathrm{w} / \mathrm{v})$ skim milk powder to block nonspecific binding of antibodies and then rinsed three times for 5 min each in TTBS. Then the membrane was probed with rabbit anti-SCIRR1 serum or together with GAPDH antibody (Santa Cruz, CA) in TTBS containing 1\% (w/v) skim milk powder for $1.5 \mathrm{~h}$ at room temperature, followed by three to five 10-min washes with TTBS 
A

M Scirr1

$1500-$

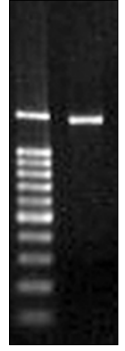

C

D

B

1 ATGTCGAGCC CTGGTATCGA TGGTGACCCC AAGCCTTCAT GCTTGCCTCG AAACGGTCTG

61 GTGAAGCTGC CTGGCCAGCC CAACGGCCTA GGCGCAGCCA GCATCACCAA GGGCACACCT 121 GCTGCCAAGA ACCGTCCTTG CCAGCCACCA CCCCCACCCA CCCTTCCACC TCCAAGCCTG 181 GCTACACCAC TGTCCCGGGT TGCTCTGGCC GGGGGGCCAT GCCCCCCAGC CAGTGGACCA 241 GCCTCAGGCC CAGTGCCTGG ACCCCCCGTG GAGCGGCAC CACTGGCCAC AGATGAGAAG 301 ATCCTTAATG GACTCTTCTG GTATTTCTCA GCGTGTGAGA AGTGCATACT AGCCCAGGTG 361 TGCAAGGCTT GGCGGCGTGT GCTCTACCAG CCCAAGTTCT GGGCAGGCCT CACGCCTGTG 421 CTGCACGCA AGGAGCTGTA CAACGTGCTG CCTGGAGGCG AGAAGGAGTT TGTGAACCTG 541 ATCTGCGAAT TCATCGACAA CTACTCGCTC TCTAAGAAGG GAGTCAAGGC CATGAGTCTC 601 ATCTGCGAAT TCATCGACAA CTACTCGCTC TCTAAGAAGG GAGTCAAGGC CATGAGTCTC 661 GTGCGCCTGG AGCTGTCAGG CTGTAACGAT TTCACCGAGG CTGGCCTGTG GTCCAGCCTC 721 ATGCGCCTGG AGCTGTCAGG CTGTAACGAT TTCACCGAGG CTGGCCTGTG GTCCAGCCTC 781 GCTGCCATCT CACAACTTCT ACCCAACCTG GCAGAGCTAA GCCTTCAGGC CTACCACGTG 841 ACTGACACGG CACTGGCCTA CTTCACAGCA CGTCAGGGCC ACAGCACCCA CACGTTGCGC 901 CTGCTCTCCT GCTGGGAGAT AACCAACCAC GGGGTGGTCA ATGTGGTGCA CAGTCTGCCC 961 AACCTCACCT CACTCAGCCT CTCGGGCTGC TCTAAGGTCA CTGATGATGG GGTGGAGCTT 021 GTAGCCGAGA ATCTGCGCAA ATTGCGCAGT CTTGACCTTT CCTGGTGCCC TCGGATCACA 081 GATATGGCAC TGGAGTATGT GGCCTGCGAC TTGCACCGAC TGGAGGAGCT CGTGCTGGAC 141 AGGTGTGTAC GCATCACGGA CACTGGTCTC AGCTACTTGT CCACCATGTC GTCCCTCCGC 201 AGCCTCTACC TGCGATGGTG CTGCCAGGTG CAGGACTTCG GGTTGAAGCA CCTCTTAGCC 1261 ATGAGAAGTT TGCGACTCTT GTCTCTAGCA GGCTGCCCGC TCCTAACCAC CACCGGGCTA 1321 TCCGGCCTAG TGCAACTGCA AGAGCTGGAG GAGCTGGAGC TGACCAACTG CCCTGGAGCC

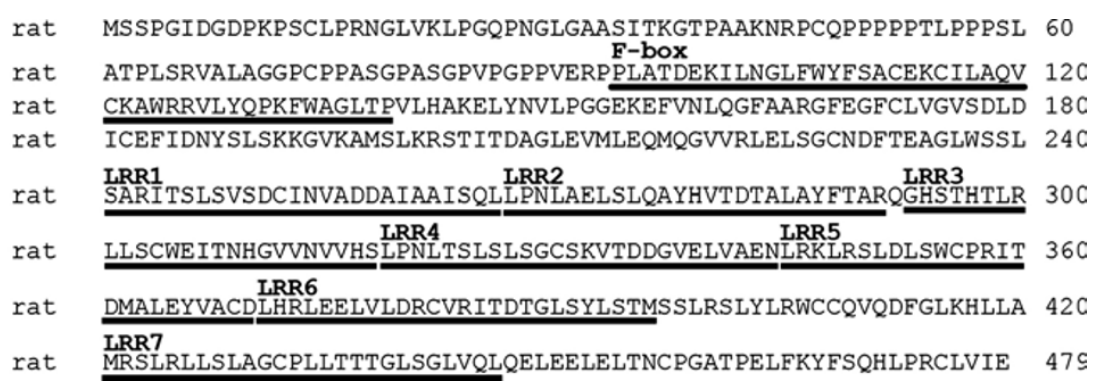

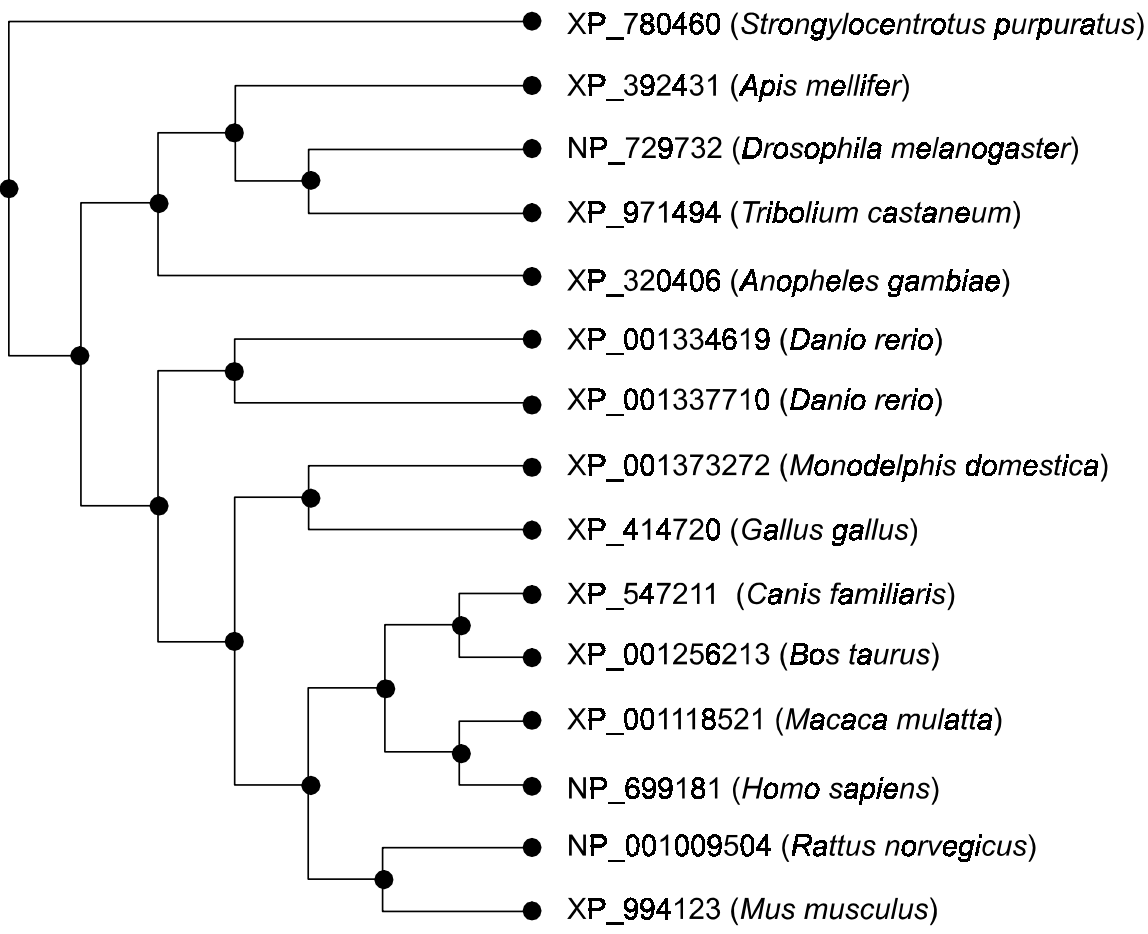

Figure 1. RT-PCR amplification of scirr1 coding sequence (CDS) from total RNA isolated from rat spinal cord 4.5 days post full-transection injury. (A) Primers specific for scirr1 CDS gave rise to DNA fragments of $\sim 1.5 \mathrm{~kb}$ (lane Scirr1). (B) Nucleotide sequence of full-length scirr1 CDS. The primer sequences used to clone the CDNA are underlined. The initiate and stop codon is shown in boldface. (C) Protein sequence of rat SCIRR1. The predicted F-box and LRR motifs are underlined and labeled with their names. (D) The fast minimum evolution tree of the homologies of rat SCIRR1 protein. The proteins predicted by computer analysis are not underlined. The proteins are labeled with their scientific names and accession numbers in the NCBI protein reference sequence database. 
alone. Membrane was then incubated for $1 \mathrm{~h}$ with the HRP-conjunct sheep anti-rabbit secondary antibody also diluted in TTBS containing 1\% (w/v) skim milk powder, followed by three to five 5-min washes with TTBS. After the final wash, immunoreactive proteins were detected by the enhanced chemiluminescence system (ECL, Amersham Pharmacia) and serial exposures were made to $\mathrm{X}$-ray film (X-Omat BT Film; Kodak).

\section{Immunohistochemistry}

With the same procedure described in 'in situ hybridization histochemistry', $30-\mu \mathrm{m}$ frozen coronal sections at the T11 and L2 levels were prepared from the sham-operated rats and injured rats at days 1, 3 and 5 post full-transection of spinal cord. After washing 3 times with PBS and treatment with $0.1 \mathrm{M}$ glycin in PBS for 5 min, the sections were put in PBS containing $0.3 \%$ TritonX-100 for 30 min. Rabbit anti-SCIRR1 polyclonal antibodies were incubated on frozen sections $(10 \mu \mathrm{m})$ at $4^{\circ} \mathrm{C}$ overnight. Finally, the sections were rinsed with tap water, mounted, dehydrated, viewed with an Olympus BX50 microscope, and photographed using a digital camera (Olympus C7070). The signal was detected by chemiluminescence.

\section{Results}

\section{scirr1 encodes a novel F-box and leucine-rich repeat protein}

Blasting against the rat genome sequence, the original EST sequence (GenBank Accession no. CV463503) of scirr1 was mapped to chromosome $10 q 12$. Sequence around the EST sequence was analyzed by the GenScan (Burge and Karlin, 1997) and HMMgene (Krogh, 1997) web servers, both giving the same prediction of a coding region spanning the EST sequence. So we designed primers based on the predicted $1440 \mathrm{bp}$ CDS sequence and subcloned the expected fragment (Figure 1A) from post-transection day 4.5 rat spinal cord RNA. After verification by DNA sequencing, the sequence (Figure 1B) was deposited at GenBank under the accession number NM 001009504. Then the translated 479 aa protein sequence of SCIRR1 was used to blast against the NCBI protein reference sequence database searching for homologous proteins. Our BLAST search resulted in 14 ortholog proteins (Table 1) which were conserved in 13 species from echinoderm to insect and human with homology levels varied from $70 \%$ (Strongylocentrotus purpuratus and Apis mellifera) to 99\% (Mus musculus). Although 11 of them were proteins predicted by automated com-

Table 1. Homologous proteins of SCIRR1.

\begin{tabular}{lll}
\hline \multicolumn{1}{c}{ Accession $^{\text {a }}$} & \multicolumn{1}{c}{ Description } & \multicolumn{1}{c}{ Species (common name) } \\
\hline NP_001009504 & F-box and leucine-rich repeat protein 16 & Rattus norvegicus (Norway rat) \\
XP_994123 & PREDICTED: similar to F-box and leucine-rich repeat protein 16 & Mus musculus (house mouse) \\
XP_547211 & PREDICTED: similar to F-box and leucine-rich repeat protein 16 & Canis familiaris (dog) \\
NP_699181 & F-box and leucine-rich repeat protein 16 & Homo sapiens (human) \\
XP_001118521 & PREDICTED: similar to F-box and leucine-rich repeat protein 16 & Macaca mulatta (rhesus monkey) \\
XP_001256213 & PREDICTED: similar to F-box and leucine-rich repeat protein 16 & Bos taurus (cattle) \\
XP_001373272 & PREDICTED: similar to possible G-protein receptor & Monodelphis domestica \\
& & (gray short-tailed opossum) \\
XP_414720 & PREDICTED: similar to possible G-protein receptor & Gallus gallus (chicken) \\
XP_001334619 & PREDICTED: similar to possible G-protein receptor & Danio rerio (zebrafish) \\
XP_001337710 & PREDICTED: similar to spinal cord injury and regeneration & Danio rerio (zebrafish) \\
XP_780460 & related protein 1 & SREDICTED: similar to spinal cord injury and regeneration \\
XP_971494 & related protein 1 & (purple urchin) \\
NP_729732 & CG32085-PA & Tribolium castaneum (red flour beetle) \\
XP_320406 & ENSANGP00000016969 & Drosophila melanogaster (fruit fly) \\
XP_392431 & PREDICTED: similar to CG32085-PA & Anopheles gambiae str PEST \\
\hline
\end{tabular}

${ }^{a}$ The accession number in the NCBI protein reference sequence database. 
putational analysis, their fast minimum evolution tree (Figure 1D), constructed by the Blast Tree View Widget at NCBI, accorded with the currently accepted evolution of species.

To predict its function, the amino acid sequence of SCIRR1 was subjected to the InterPro motif analysis web server (http://www.ebi.ac.uk/InterProScan/). SClRR1 was found to bear an F-box signature (aa 94139 ) in the $\mathrm{N}$ terminal region and seven Leucine-rich repeat (LRR) motifs (aa 241-266, 267-291, 293-318, $319-344,345-370,371-396$ and $421-446$ ) in the $C$ terminal region (Figure $1 \mathrm{C}$ ), which is one of the typical motif architectures of the substrate adaptors in SCF (SKP1-CULLIN-F-box) E3 ubiquitin ligase complexes.

scirr1 mRNA is widely expressed in adult tissues Since scirr1 represented a novel gene, we sought to determine its distribution in adult tissues. We extracted RNA from various organs, including skeletal muscle, heart, liver, thymus, spleen, pancreas, kidney, stomach, lung, small intestine, large intestine, testis, cerebra, cerebellum, brain stem and spinal cord, and performed RT-PCR analysis. Results from this experiment revealed wide expression throughout various types of tissue except for thymus (Figure 2A).

\section{In spinal cord, scirr1 mRNA is expressed in gray matter neurons}

Is scirr1 expressed also ubiquitously in spinal cord? To reveal the cellular origin(s) of scirr1 mRNA in the spinal cord, in situ hybridization was used in conjunction with antisense riboprobes and sections derived from the T10 segment of intact rat spinal cord. scirr1 expression in spinal cord is localized in the gray matter (Figure 2B). At higher magnification it is evident that these scirr1-expressing cells are neurons, especially the large motor neurons in the ninth layer (Figure 2C).

\section{scirr1 mRNA is specifically expressed and developmentally regulated in CNS during embryonic stages}

Since repair is essentially a recapitulation of development, we wanted to determine whether and how scirr1 is expressed during embryonic nervous system development. To address this, we performed whole-mount in situ hybridization on mouse embryos of E9.5, E10, E10.5, E11.5, E12 and E13 (Figure 3). The results clearly revealed its specific expression in the central nervous system during the stages of E10-E13. scirr1 expression was detected initially in ventral aspects of telencephalon at the E10 stage.
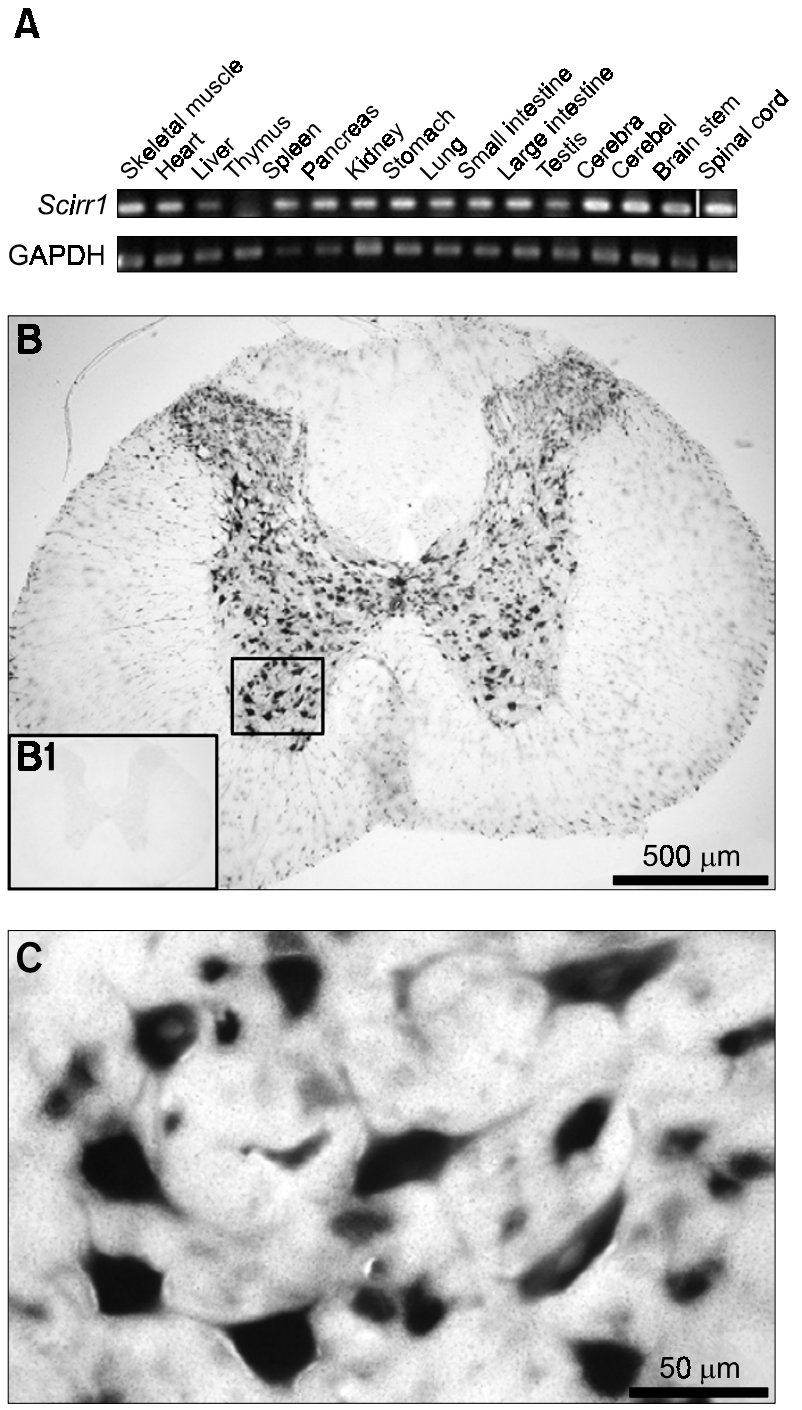

Figure 2. Expression of scirr1 mRNA in adult rat tissues. (A) Wide expression of scirr1 mRNA in adult rat tissues. Total RNA isolated from various adult tissue samples was analyzed via semiquantitative RT-PCR with GAPDH as a control marker. (B) Expression of scirr1 mRNA in adult rat spinal cord gray matter neurons. Sections obtained from intact rat spinal cord were hybridized with a scirr1 antisense riboprobe. (B1) A sense probe was applied on an section obtained from intact rat spinal cord as background control. (C) The area of the box in panel $B$ is enlarged and shown in panel $C$ where the large motor neurons in the ninth layer are shown deeply stained.

During the stages of E11.5-E12, the positive stain dispersed to a wider area of the forebrain, while strong expression was concentrated in the ventral parts of the midbrain and hindbrain. At the E13 stage, the stain was detected spreading throughout all of the brain areas at a further reduced density, while expression was first seen in ventral aspects of the spinal cord (indicated by a black arrowhead). A 


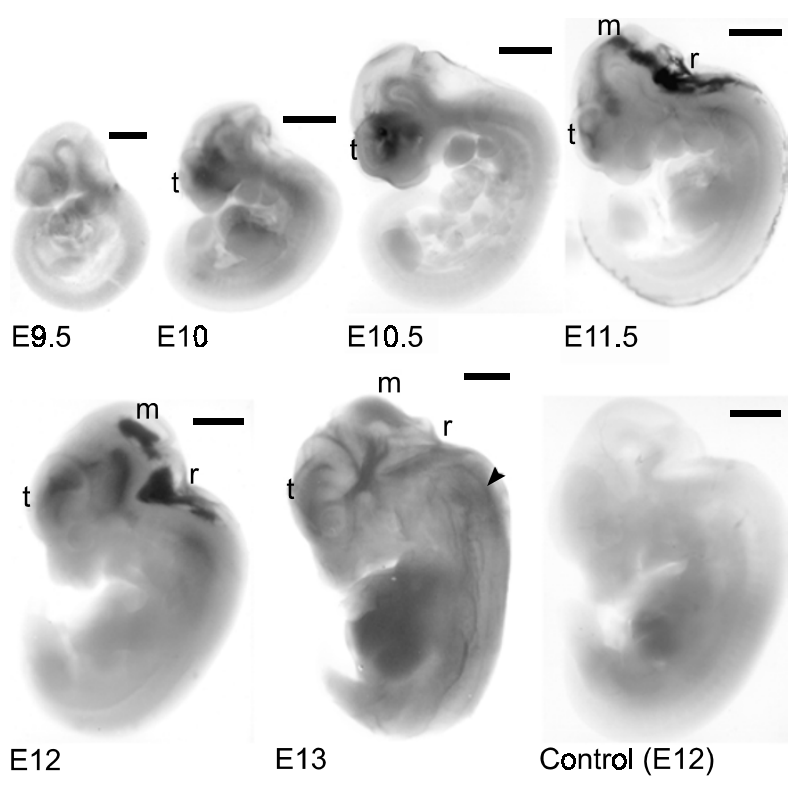

Figure 3. Expression of scirr1 in mouse embryo by whole-mount in situ hybridization, using digoxigenin-labeled scirr1 riboprobes on mouse embryos at different stages of development from E9.5 to E13. scirr1 expression was detected initially in ventral aspects of telencephalon at stage of E10. During stages of E11.5-E12, the stain dispersed widely in forebrain, while strong expression was detected in the ventral parts of midbrain and hindbrain. At stage of E12, much stronger stain was found in telencephalon, midbrain and hindbrain. At stage of E13, the stain was detected throughout the whole brain areas in a reduced density, while expression was first seen in ventral aspects of the spinal cord (black arrowhead). $t$, telencephalon; $m$, mesencephalon; $r$, rhombencephalon. A sense probe was applied on an E12 embryo as background control. Bar of E9.5 is $0.5 \mathrm{~mm}$. Bars of other stages are all $1 \mathrm{~mm}$.

sense probe was applied on an E12 embryo as background control and no expression was detected. So, scirr1 mRNA emerged in ventral parts of telencephalon, midbrain, hindbrain and spinal cord sequentially, in accordance with their development sequence. And then in each brain area, along with development, expression of scirr1 arose gradually in increasingly wider area.

\section{Rabbit anti-SCIRR1 serum binds SCIRR1 with high specificity}

Antibody is needed to invest protein expression characteristics of SCIRR1. Using the recombinant pGEX4T-2 vector encoding GST-SCIRR1 fusion protein, we obtained the fusion protein from $E$. coli BL21. Following removal of the GST tag by thrombin, the purified SCIRR1 protein was used as antigen for rabbit anti-SCIRR1 serum preparation. Using the prepared rabbit anti-SCIRR1 serum, only one single positive band, representing the same molecular weight as SCIRR1 (about 51.8 KDa), was detected

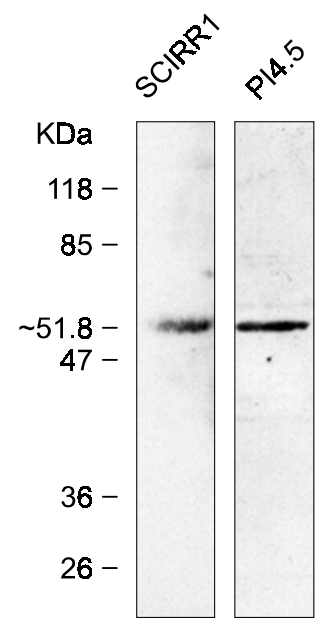

Figure 4. Verification of the specificity of rabbit anti-SCIRR1 serum by Western analysis. SCIRR1, the purified SCIRR1 protein with calculated molecular weight about $51.8 \mathrm{KDa}$. PI4.5, the total protein extracted from post-transection day 4.5 rat spinal cord. The single positive band detected in lane PI4.5 indicated rabbit anti-SCIRR1 serum recognizes SCIRR1 specifically.

in Western blot assay of either the purified SCIRR1 protein or the total protein extracted from post-transection day 4.5 rat spinal cord (Figure 4). So we successfully obtained an antiserum that is highly specific for SCIRR1.

\section{SCIRR1 is located in cytoplasm}

To get a first insight in the cellular function of SCIRR1, we established its subcellular localization. Transient transfections with the SCIRR1-EGFP construct and parental pEGFP-N1 plasmids were carried out in PC12 cells. The cytoplasm of cells transfected with SCIRR1-EGFP was labeled exclusively, indicating the capture of SCIRR1-EGFP fusion protein in cytoplasm (Figure 5A). Transfection with the parental vector resulted in diffuse labeling throughout the cells, demonstrating active EGFP translation with no specific subcellular localization (Figure $5 B$ ).

To further determine its location in primary neurons, immunohistochemical assay was performed on rat spinal cord section with the previously prepared anti-SCIRR1 serum. Similar to the location of SCIRR1EGFP in PC12 cells, the positive stain was only found in cytoplasm and processes (Figure 5C, D).

\section{Spatial and temporal variation of SCIRR1 protein in spinal cord after injury}

To infer its possible role in spinal cord injury and/or regeneration, we set to determine the spatial and temporal variation of SCIRR1 in neurons at particular sections of injured spinal cord. To address this, 

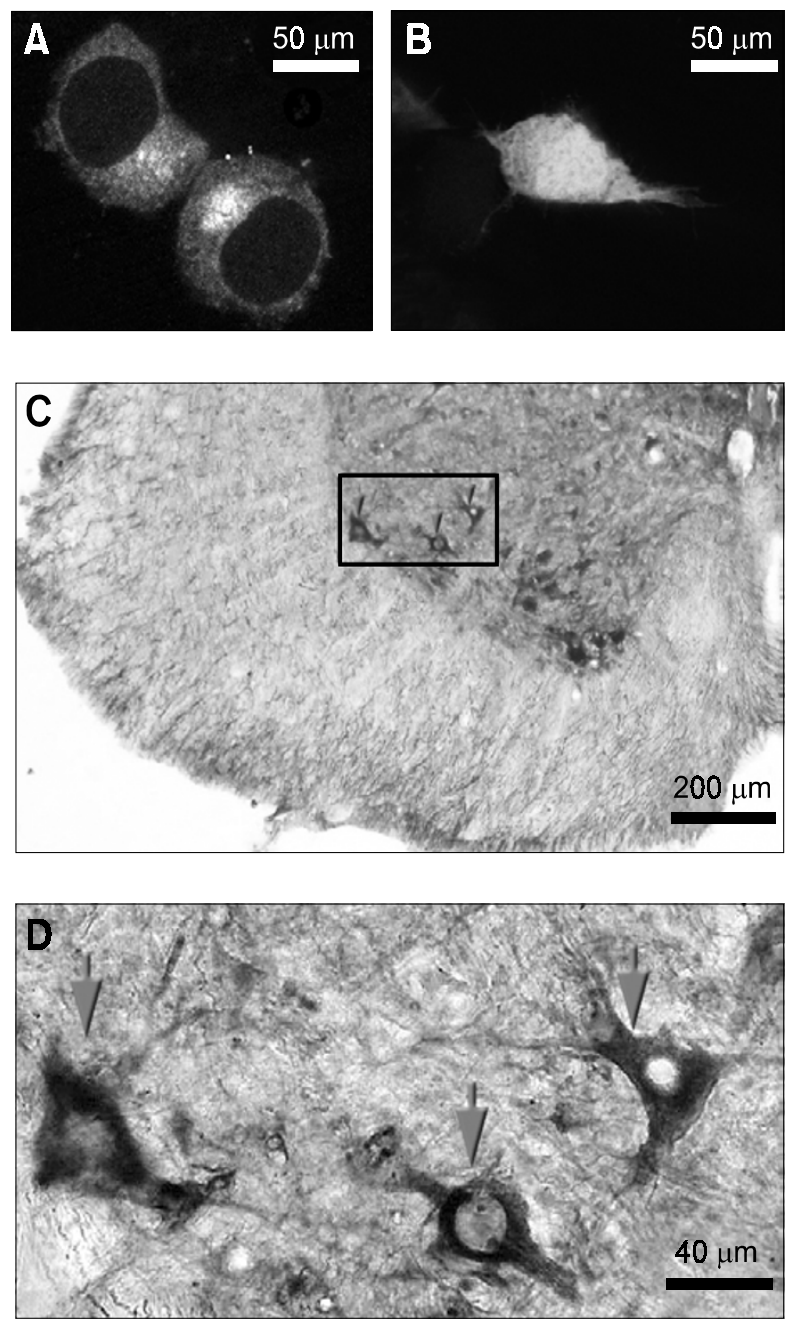

Figure 5. Cytoplasm localization of SCIRR1 protein. PC12 cells were transiently transfected with the SCIRR1-EGFP plasmid encoding an EGFP/SCIRR1 fusion and the parental pEGFP-N1 vector. In cells transfected with SCIRR1-EGFP plasmid, the encoded SCIRR1-EGFP fusion localizes in the cytoplasm. No signal found in the nucleus (A). In cell transfected with pEGFP-N1 vector, the vector EGFP is dispersed throughout the cell body (B). Cytoplasm localization of SCIRR1 was further verified by immunohistochemical assay in spinal cord section using rabbit anti-SCIRR1 serum (C,D). The area of the box in panel $C$ is enlarged and shown in panel $D$. Red arrows in panels $C$ and $D$ show the specific stain in neuron cytoplasm and processes.

we performed an immunohistochemical assay on rat spinal cord T11 (Figure 6A-D) and L2 (Figure 6E-H) sections derived respectively from intact (Figure 6A, E) and post-transection spinal cord at days 1 (Figure 6B, F), 3 (Figure 6C, G) and 5 (Figure 6D, H). SCIRR1 was up-regulated in most neurons at both T11 and L2 sections obviously after transection injury, reaching its expression peak 3 days later.

Interestingly, the positive stain in most of the neurons at the L2 section was much deeper than that at the T11 section at the same time post injury.
Considering the lighter positive stain in most of the neurons at the L2 normal control section than that at the T11 normal control section, the relative expression of SCIRR1 should be stronger in most neurons at L2 section than in that at T11 section at the same time post injury.

\section{Discussion}

In a previous study, we identified a novel rat EST sequence up-regulated after transection trauma of spinal cord (Ma et al., 2006). And the present study was designed to try to identify its full coding sequence and make a general characterization in context of CNS and spinal cord, which will provide useful clues for further study on its role in spinal cord injury and/or regeneration process.

Aided by bioinformatics, we successfully predicted and cloned the full CDS sequence of the scirr1 gene. Homology analysis revealed that there were 14 homologues conserved from echinoderm to insect and human (Table 1 and Figure 1D). This indicates that scirr1 may function in some basic cellular processes. Among these homologues, 11 were predicted by automatic computer analysis. Except for the sequences, there is presently no other information of these homologues available. So this study gives the first report of this gene's biological characters.

As expression profile and its variations under different circumstances should be informative to deduce the possible role of a new gene, we examined scirr1's tissue distribution, cellular expression, intracellular expression, developmental expression and expression modification after spinal cord injury. As seen in Figure 3, scirr1 mRNA emerged in telencephalon, midbrain, hindbrain and spinal cord sequentially accompanying their initial development, and then spreading to an increasingly wider area in each brain area along with the early development period. In view of its expression in adult neurons instead of glial cells (Figure 2B and C), this developmentally regulated expression profile indicate that scirr1 may be expressed in neural precursor cells which migrate to progressively broader area differentiating into neurons, along with the same migration of much more amount glial cells originated from neuroepithelial cells. Further, SCIRR1 protein was found to be up-regulated in a distance-to-injury related manner in response to full transection of spinal cord (Figure 6). At the same time post injury, the more distance away from the injury site, the stronger up-regulation of SCIRR1 protein was found. This distance-to-injury related manner should be induced by distinctive environments around the examined T11 and L2 sections. It is well-known that changes in 

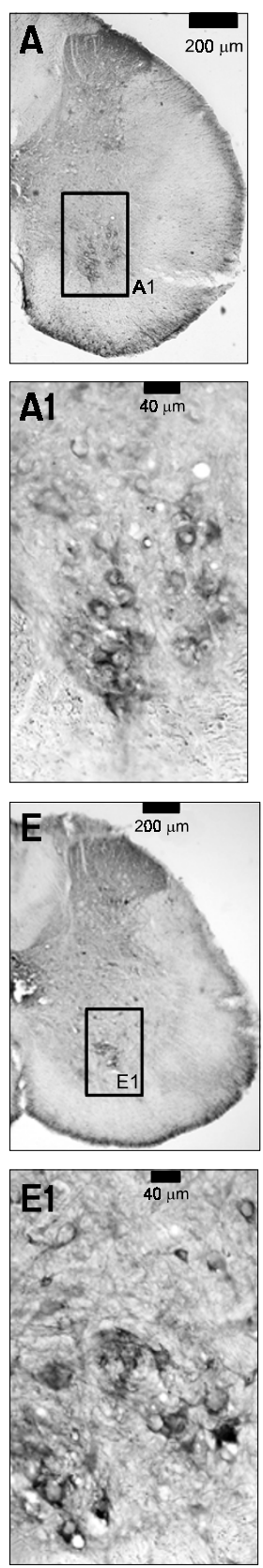
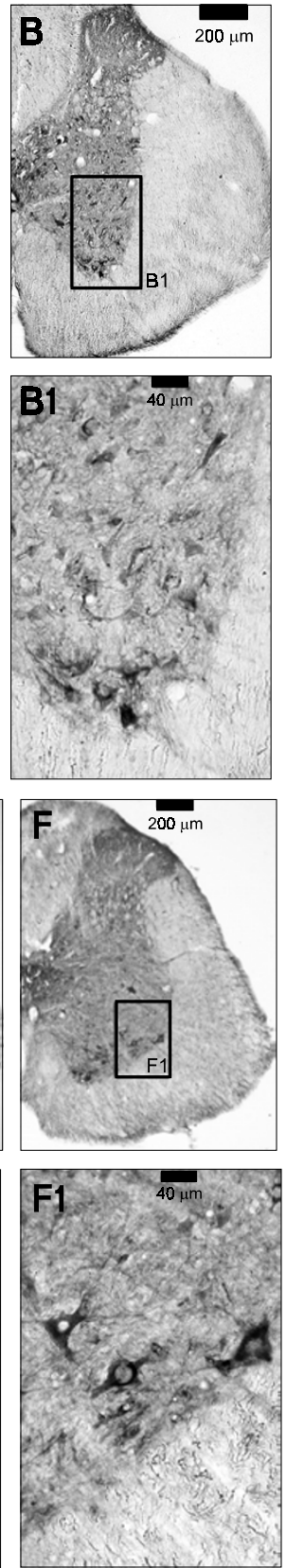
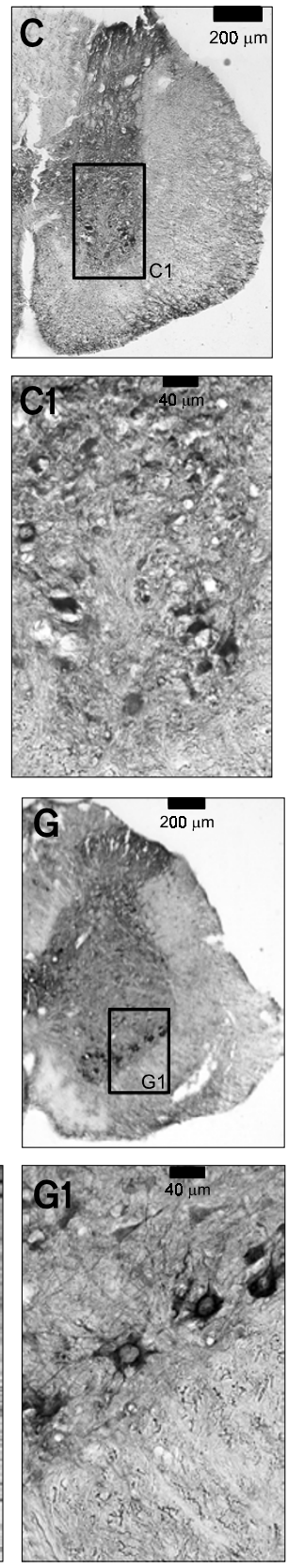
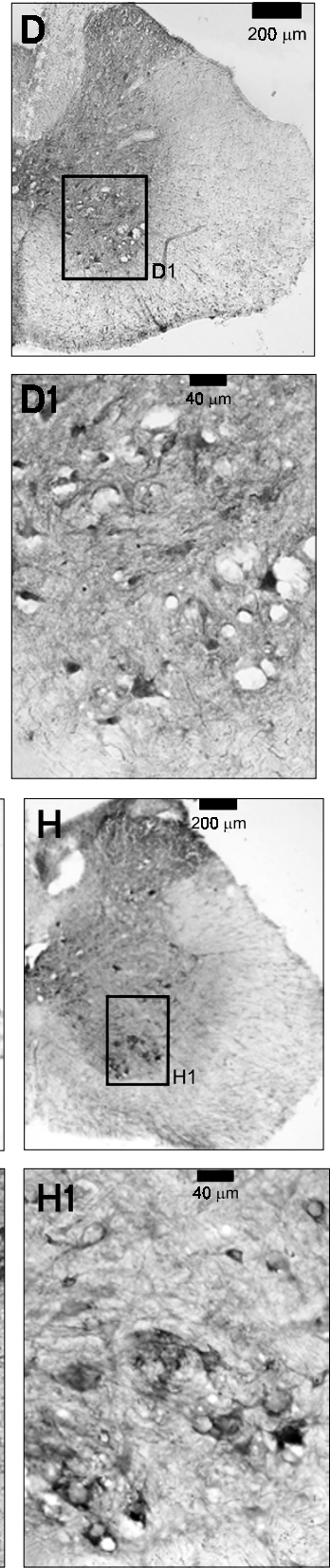

Figure 6. Immunohistochemical analysis of altered expression of SCIRR1 protein in rat spinal cord neurons after full-transection injury, using selfmade rabbit anti-SCIRR1 serum. $A, E$, normal control; $B, F, 1$ day post-injury; $C, G, 3$ days post-injury; $\mathrm{D}, \mathrm{H}, 5$ days post-injury. Expression of SCIRR1 protein in most neurons were enhanced after injury and reached its peak 3 days post-injury at spinal cord levels of T11 (A-D) and L2 (E-H). At 5 days post-injury, SCIRR1 were downregulated slightly in comparison with the early days. Compared to that in the corresponding normal control, the relative expression of SCIRR1 protein was found, at the same time post injury, to be stronger in most of the neurons at section L2 than in those at section T11. The area of the black boxes are enlarged and shown in the immediate bottom panels respectively, which show alteration of SCIRR1 protein expression in the neurons. gene expression in the neurons distal to the injury site could reflect not only the regeneration response but also inflammatory and neuroprotective responses by diffusible signals from the injury site or by loss of synaptic input. In recent years, many investigators have observed the characteristic inflammatory response that emerged robustly at the injury site and spread to the distal cord in a lower level (Carmel et al., 2001; Aimone et al., 2004; De Biase et al., 2005). L2 section is farther from the transected section (between T9 and T10) than the T11 one. So L2 section should have weaker inflam- matory and neuroprotective responses than the T11 section. If up-regulation of SCIRR1 is induced by inflammatory and neuroprotective responses, the positive stain in the neurons at L2 section should be much lighter than that at the T11 section at the same time post injury, which is opposed to what we have observed. On the other hand, regeneration response is usually postponed by injury reaction in nerve system. As observed by Velardo et al. (2004) tissue repair transcripts were up-regulated dramatically only by 3 days post injury of spinal cord. Genes associated with putative regenerative responses in the 
spinal cord, such as phosphodiesterase 4, nestin, glia-derived neurite promoting factor and growth associated protein 43 , were found to increase significantly in a higher level and earlier stage in the distal segment than in the injury site (Carmel et al., 2001; Grossman et al., 2001). T11 section is much closer to the injured site, so regeneration response here should occur later than $\mathrm{L} 2$ section. If up-regulation of SCIRR1 is involved in regeneration, the extent of incensement in neurons at $\mathrm{L} 2$ section should be much larger than that one at T11 section, which is in harmonic with the experimental results. Together with its highest expression at day 3 after injury and the developmentally modulated specific expression pattern in CNS, there is much more possibility for SCIRR1 to take regeneration related role in the subsequent processes following spinal cord injury, although direct evidence is needed.

Interestingly, scirr1 mRNA was found to be expressed in various adult tissues (Figure 2A). In view of its developmentally regulated specific expression in early embryonic CNS, this may suggest that scirr1 functions in an extraordinary molecular mechanism that is basic for adult tissues but very important for CNS development exclusively.

To explore its possible molecular functional mechanism, SCIRR1 protein sequence was subjected to motif analysis. And the result revealed that SCIRR1 possesses the typical motif architectures of the substrate adaptors in SCF E3 ubiquitin ligase complexes, indicating that SCIRR1 may be a new substrate adaptor that recruits substrates for ubiquitination by the SCF complex. The ubiquitinated substrates are then transferred to $26 \mathrm{~S}$ proteasome for degradation. This modification and degradation system, named the ubiquitin/proteasome system, is a crucial determinant of virtually all biological processes in eukaryotes, exerting controls over stability of numerous regulators including cell cycle proteins (e.g., cyclins, CDK inhibitors and replication factors), transcription factors (e.g., $I_{\kappa} B$ and $\beta$-catenin), tumor suppressor proteins (e.g., Rb and p53), oncoproteins (e.g., Myc and Jun), membrane proteins (e.g., growth factor receptors) and many more (Willems et al., 2004). Moreover, the ubiquitin/proteasome system has been found to be required for neuronal pathfinding during development, regulation of synaptic branching and number, and synaptic plasticity (Johnston and Madura, 2004).

Substrate adaptors of SCF can be classified into three major classes, of which one is FBXL with a typical F-box and multiple LRRs architecture (Jin et al., 2004). Up to now, including SCIRR1, there were totally 22 members of FBXL reported (Jin et al., 2004). And only 4 members have been characterized: SKP2/FBXL1 is restricted in nuclei and promotes cell cycle procession during $\mathrm{S}$ and $\mathrm{G} 2$ phases (Zhang et al., 1995; Lisztwan et al., 1998; Yu et al., 1998); FBXL2 is located in the cytosol around nuclei and function in the maintenance of cell growth-arrest (llyin et al., 1999); FBXL3 is expressed specifically in brain and testis (Ilyin et al., 2000); and FBXL13 is characterized as candidate myeloid tumor suppressor (Curtiss et al., 2005). So, despite the structural homology, FBXLs likely target different proteins and consequently play distinct roles as argued by their distinctive expression pattern. And the structural basis of functional divergences is mainly ascribed to their distinctive LRRs domains (Willems et al., 2004). Since different adaptors recognize distinct substrates, the discovery of scirr1 may suggest an expansion of substrates and subsequently pathways regulated by the ubiquitin/proteasome system. Except for SKP2 and FBXL2, SCIRR1 is the third FBXL to have intracellular location addressed by experimental method. Recently, many genes involved in the ubiquitin/proteasome system have been found to be up-regulated after spinal cord injury (De Biase et al., 2005). Together with its possible role in the development of CNS and in the regeneration of spinal cord, scirr1 should be an interesting target for further studies.

In summary it was demonstrated 1) that scirr1 is a novel gene that encodes a 479-aa cytoplasm protein, 2 ) that scirr1 is expressed widely in various adult rat tissues, 3) that scirr1 is expressed mainly in neurons within the spinal cord, 4) that scirr1 is specifically expressed and developmentally regulated in CNS during early embryonic period, 5) that SCIRR1 protein is up-regulated after spinal cord injury, and 6) that SCIRR1 possibly is a FBXL protein functioning in development and regeneration of the mammalian CNS through ubiquitin/proteasome pathway.

\section{Acknowledgement}

This study was supported by the National Natural Science Foundation of China (Grant No. 30670791), the Chinese National Key Project of Basic Research (Grant No. 001CB510206), and the National Key Project of the Chinese Ministry of Health (Grant No. WKZ-2001-1-18).

\section{References}

Aimone JB, Leasure JL, Perreau VM, Thallmair M. Spatial and temporal gene expression profiling of the contused rat spinal cord. Exp Neurol 2004;189:204-21

Beattie MS, Hermann GE, Rogers RC, Bresnahan JC. Cell death in models of spinal cord injury. Prog Brain Res 2002;137:37-47

Burge C, Karlin S. Prediction of complete gene structures in human genomic DNA. J Mol Biol 1997;268:78-94 
Carmel JB, Galante A, Soteropoulos P, Tolias P, Recce M, Young W, Hart RP. Gene expression profiling of acute spinal cord injury reveals spreading inflammatory signals and neuron loss. Physiol Genomics 2001;7:201-13

Curtiss NP, Bonifas JM, Lauchle JO, Balkman JD, Kratz CP, Emerling BM, Green ED, Le Beau MM, Shannon KM. Isolation and analysis of candidate myeloid tumor suppressor genes from a commonly deleted segment of $7 q 22$. Genomics 2005;85:600-7

De Biase A, Knoblach SM, Di Giovanni S, Fan C, Molon A, Hoffman EP, Faden Al. Gene expression profiling of experimental traumatic spinal cord injury as a function of distance from impact site and injury severity. Physiol Genomics 2005;22:368-81

Grossman SD, Rosenberg LJ, Wrathall JR. Temporal-spatial pattern of acute neuronal and glial loss after spinal cord contusion. Exp Neurol 2001;168:273-82

Hayashi M, Ueyama T, Nemoto K, Tamaki T, Senba E. Sequential mRNA expression for immediate early genes, cytokines, and neurotrophins in spinal cord injury. J Neurotrauma 2000;17:203-18

Ilyin GP, Rialland M, Glaise D, Guguen-Guillouzo C. Identification of a novel Skp2-like mammalian protein containing F-box and leucine-rich repeats. FEBS Lett 1999;459:75-9

Ilyin GP, Rialland M, Pigeon C, Guguen-Guillouzo C. cDNA cloning and expression analysis of new members of the mammalian F-box protein family. Genomics 2000;67:40-7

Jin J, Cardozo T, Lovering RC, Elledge SJ, Pagano M, Harper JW. Systematic analysis and nomenclature of mammalian F-box proteins. Genes Dev 2004;18:2573-80

Johnston JA, Madura K. Rings, chains and ladders: ubiquitin goes to work in the neuron. Prog Neurobiol 2004;73:227-57

Krogh A. Two methods for improving performance of an HMM and their application for gene finding. In Proceedings of the Fifth International Conference on Intelligent Systems for Mole- cular Biology (Gaasterland T, Karp P, Karplus K, Ouzounis C, Sander C, Valencia A, eds), 1997, 179-86, The American Association for Artificial Intelligence Press, Menlo Park, California

Lisztwan J, Marti A, Sutterluty H, Gstaiger M, Wirbelauer C, Krek W. Association of human CUL-1 and ubiquitinconjugating enzyme CDC34 with the F-box protein p45 (SKP2): evidence for evolutionary conservation in the subunit composition of the CDC34-SCF pathway. EMBO J 1998;17: 368-83

Ma Z, Liu T, Li X, Zhou T, Xiao L, Que H, Tian D, Jing S, Liu S. Identification of up-regulated genes after complete spinal cord transection in adult rats. Cell Mol Neurobiol 2006;26:277-88

Profyris C, Cheema SS, Zang D, Azari MF, Boyle K, Petratos $S$. Degenerative and regenerative mechanisms governing spinal cord injury. Neurobiol Dis 2004;15:415-36

Velardo MJ, Burger C, Williams PR, Baker HV, Lopez MC, Mareci TH, White TE, Muzyczka N, Reier PJ. Patterns of gene expression reveal a temporally orchestrated wound healing response in the injured spinal cord. J Neurosci 2004;24: 8562-76

Willems AR, Schwab M, Tyers M. A hitchhiker's guide to the cullin ubiquitin ligases: SCF and its kin. Biochim Biophys Acta 2004;1695:133-70

Yu ZK, Gervais JL, Zhang H. Human CUL-1 associates with the SKP1/SKP2 complex and regulates p21 (CIP1/WAF1) and cyclin D proteins. Proc Natl Acad Sci U S A 1998;95:11324-9

Zhang H, Kobayashi R, Galaktionov K, Beach D. p19Skp1 and p45Skp2 are essential elements of the cyclin A-CDK2 S phase kinase. Cell 1995;82:915-25

Zhao Z, Huang X, Li N, Zhu X, Chen S, Cao X. Direct cloning of cell differential expression genes with full-length by a new strategy based on the multiple rounds of 'long distance' polymerase chain reaction and magnetic beads mediated subtraction. J Biotechnol 1999;73:35-41 